\title{
Encephalocraniocutaneous lipomatosis
}

INSERM

\section{Source}

INSERM. (1999). Orphanet: an online rare disease and orphan drug data base.

Encephalocraniocutaneous lipomatosis. ORPHA:2396

A rare, genetic skin disease characterized by the ocular, cutaneous, and central nervous system anomalies. Typical clinical features include a well-demarcated hairless fatty nevus on the scalp, benign ocular tumors, and central nervous system lipomas, leading sometimes to seizures, spasticity, and intellectual disability. Nevus psiloliparus, focal dermal hypo- or aplasia, eyelid skin tags, colobomas, abnormal intracranial vessels, hemispheric atrophy, porencephalic cyst, and hydrocephalus have also been associated. 